\title{
The system of values of paediatricians, paediatricians- in-training, and medical students
}

\author{
Elżbieta Szczepanik1, Jakub Ryszard Stempień2, Marcin Tkaczyk1,3 \\ 'Department of Paediatrics, Immunology, and Nephrology, Polish Mother's Memorial Hospital Research Institute, Lodz, Poland \\ 2Department of Rural and Urban Sociology, University of Lodz, Lodz, Poland \\ ${ }^{3}$ Division of Didactics in Paediatrics, Medical University of Lodz, Lodz, Poland
}

\section{ABSTRACT}

\begin{abstract}
Aim of the study: Ethics and a system of values are crucial for doctors in their professional life. The aim of the presented study was to compare the system of values of medical students and paediatricians, paediatricians in-training, and other specialist doctors working in paediatric departments. Additionally, the position of profession in the hierarchy of life values in the groups mentioned above was analysed.

Material and methods: A total of 379 respondents participated in the study - 151 resident paediatricians and specialists working in paediatric departments in the tertiary paediatric reference centre and 228 students of the Medical Faculty. A professionally designed questionnaire consisting of 14 questions in two versions was used. Questions concerning the issues of values important in life and the axiological sources pivotal in worldview shaping were analysed.

Results: Students most often chose: domestic bliss (66\%), good health (35\%), and helping other people (34\%). The physicians listed the values accordingly: domestic bliss (75\%), retaining good health (48\%), and profession (29\%). Students ranked fame and success higher, while physicians appreciated a decent life more. The axiological sources were concordant in both groups, namely one's own reflections and parents' opinion. We found no statistical differences between students and physicians. A strong correlation of answers in both groups was proved using Spearman's rank correlation coefficient $\left(r_{s}=0.96\right)$.

Conclusions: The study showed that professional work for medical students and doctors dealing with children held a high place in the system of values but was not the most important thing in life. Domestic bliss, retaining good health, or a decent life were more important. According to the study it can be hypothesised that the system of values represented by paediatricians does not change significantly in the course of professional training although one cannot generalise to the whole country because the study was from a single centre.
\end{abstract}

\section{KEY WORDS:}

medicine, paediatrics, job, morality, ethics.

\section{INTRODUCTION}

Ethics and a system of values are undoubtedly crucial for doctors in their professional life. Medical students and professionals taking care of children ought to present a broad ethical knowledge as well as the ability to apply it in everyday situations while working or studying. It is common knowledge that medical students and doctors are expected to possess impeccable manners and a proper ethical attitude [2]. Where is the rightful place of

\section{ADDRESS FOR CORRESPONDENCE:}

Elżbieta Szczepanik, Department of Paediatrics, Immunology, and Nephrology, Polish Mother's Memorial Hospital Research Institute, 281/289 Rzgowska St., 93-338 Lodz, Poland, e-mail: szczepanikelzbieta@wp.pl 
profession? Can a person who cherishes their profession the most present the correct ethical attitude, or should medical professionals keep a distance from their duties in order to retain a good work-life balance, which can undoubtedly support ethically correct behaviour?

Being a doctor is closely associated with high social esteem. Doctors are expected to be responsible, show respect for people's dignity, and simply be professional. In $201371 \%$ of respondents according to the Centre for Public Opinion Research (CBOS) reported high esteem for doctors as an occupational group [3]. On the other hand, doctors as professionals are being less and less revered, which is obvious when you take another CBOS report into consideration. In 1999 the most respected professions were university professor, doctor, teacher, and judge [4]. In the 2013 CBOS report the profession of doctor is ranked far behind professions such as university professor, firefighter, miner, nurse, or even highly qualified blue-collar worker [3].

Decreasing social esteem for doctors has a negative influence on satisfaction with performing the profession and augments the doctors' feeling of social injustice. Both of these phenomena have already been described in another article based on the same group of respondents [5]. Could an erroneous ethical attitude presented by doctors be blamed for the diminishing social respect of the profession? Conversely, the hierarchy of values unveiled undoubtedly the doctors' right to enjoy a high social esteem.

The aim of the study was to discover the axiological sources of ethics for medical students and doctors working in paediatric departments as well as to compare the details of their system of values.

\section{MATERIAL AND METHODS}

In the academic year 2013/2014 in Lodz a total of 379 medical students and doctors participated in the study by answering 14 questions. The respondents were divided into two groups: 1) resident paediatricians and specialists (paediatricians and paediatric: nephrologists, allergists, orthopaedists, and surgeons working in The Polish Mother's Memorial Hospital in Lodz, $n=151)$; 2) students of the Medical Faculty at the Medical University of Lodz $(n=228)$. Detailed characteristics of the participants are contained in Table 1 . The gender distribution did not differ between the study groups.

Participants in the study completed a specially designed questionnaire prepared by professional and experienced sociologists. There were two versions, $\mathrm{A}$ and $\mathrm{B}$, similar but not identical to avoid the risk of interactions between answers to similar questions and to obtain the most reliable data possible. For that reason, some questions were divided and placed in different questionnaires. Such a strategy seemed far more accurate than resignation from some questions or placing them in the same questionnaire. The questions were formulated so as to discover
TABLE 1. Sociodemographic characteristics of the study population

\begin{tabular}{|c|c|c|}
\hline Characteristic & $n$ & $\%$ \\
\hline Doctors & 151 & 40 \\
\hline \multicolumn{3}{|c|}{ Version of the questionnaire } \\
\hline Version A & 71 & 47 \\
\hline Version B & 80 & 53 \\
\hline Total & 151 & 100 \\
\hline \multicolumn{3}{|l|}{ Professional status } \\
\hline Resident doctor & 72 & 48 \\
\hline Specialist & 79 & 52 \\
\hline Missing data & - & - \\
\hline Total & 151 & 100 \\
\hline \multicolumn{3}{|l|}{ Sex } \\
\hline Male & 49 & 32 \\
\hline Female & 101 & 67 \\
\hline Missing data & 1 & 1 \\
\hline Total & 151 & 100 \\
\hline \multicolumn{3}{|l|}{ Year of birth } \\
\hline Median & \multicolumn{2}{|c|}{1976} \\
\hline $\operatorname{Min} / \max$ & \multicolumn{2}{|c|}{$1949 / 1988$} \\
\hline \multicolumn{3}{|c|}{ Year of medical school graduation } \\
\hline Median & \multicolumn{2}{|c|}{2000} \\
\hline $\operatorname{Min} / \max$ & \multicolumn{2}{|c|}{$1974 / 2013$} \\
\hline Medicine students & 228 & 60 \\
\hline \multicolumn{3}{|c|}{ Version of the questionnaire } \\
\hline Version A & 132 & 58 \\
\hline Version B & 96 & 42 \\
\hline Total & 228 & 100 \\
\hline \multicolumn{3}{|l|}{ Year of studies } \\
\hline First/second & 21 & 9 \\
\hline Third & 112 & 49 \\
\hline Sixth & 95 & 42 \\
\hline Missing data & - & - \\
\hline Total & 228 & 100 \\
\hline \multicolumn{3}{|l|}{ Sex } \\
\hline Male & 88 & 39 \\
\hline Female & 139 & 61 \\
\hline Missing data & 1 & 0.4 \\
\hline Total & 228 & 100 \\
\hline \multicolumn{3}{|l|}{ Year of birth } \\
\hline Median & \multicolumn{2}{|c|}{1990} \\
\hline Min/max & \multicolumn{2}{|c|}{$1985 / 1994$} \\
\hline Total & 379 & 100 \\
\hline
\end{tabular}




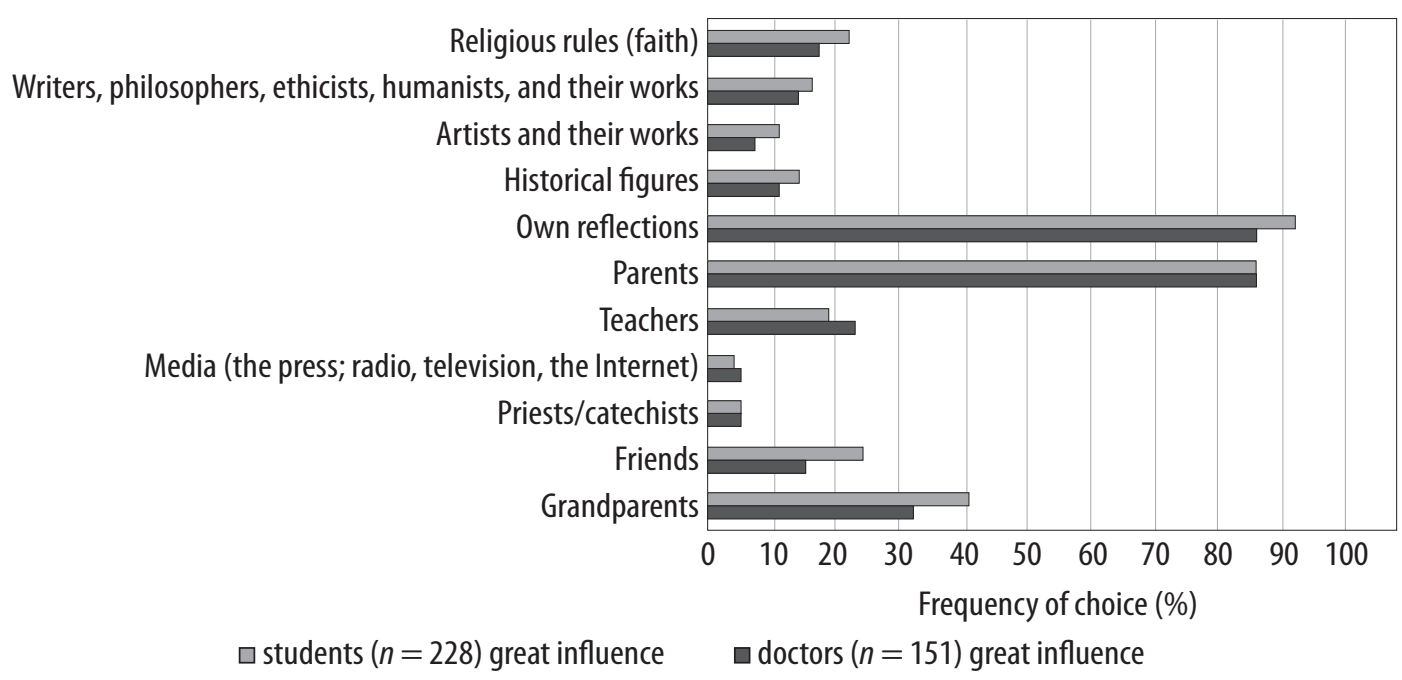

FIGURE 1. Declared influence of factors and people listed above on world-view shaping

world-view and value systems as well as role models. To analyse the answers, respondents were divided into two groups: students and doctors.

Collected questionnaires were analysed following the standards of descriptive statistics. The statistical measures applied included: structure indicators (percentage), Spearman's rank correlation coefficient, and Student's $t$-distribution for independent variables. Those measures enabled analysis of relations between answers given to certain questions and falling into one of the two key groups: medical students and practising doctors. In addition, it was possible to assess statistical differences between groups (second analysed question in version $\mathrm{A}$ ).

\section{RESULTS}

First analysed question was "What was the influence of people and factors listed below on the process of shaping your world-view?" Respondents were asked to assess the strength of listed factors that could have influenced their attitude. All of the variables were assessed individually by choosing one of the following options: great/limited/small influence/hard to say.

Medical students and doctors represented parallel axiological sources (Fig. 1). According to the declarations of the respondents, for $92 \%$ of students and $86 \%$ of doctors, their own reflections had the greatest importance for the formation of their world-view. For $86 \%$ of doctors and the same percentage of students' parents, their opinions played a crucial role in the development of normative value system. While assessing "small influence", it is obvious that religion, priests, catechists, or role models derived from art or history for both groups were of negligible importance. No significant differences between the structure of answers of analysed groups were observed. Spearman's coefficient was used to calculate the correlation of ranks. In this set of data, students and doctors answered nearly identically $\left(r_{s}=0.96\right)$.
The next question the authors analysed had two versions. In version A it was: "There is a list of several values below that play different roles in lives of certain people. Assess each and every value according to its importance for you". Values could be given scores from 1 to 7 where 1 represented "completely insignificant" and 7 for "absolutely significant". The range of answers in the studied group is shown in Figure 2 presented as arithmetic means for the assessed values. 132 students and 71 doctors answered correctly. Students placed work in the seventh position in the hierarchy of values, with an arithmetic of mean 6.02 (behind domestic bliss -6.7 , retaining good health -6.69 , education -6.36 , decent life -6.22 , calm -6.08 ). Doctors ranked it a bit higher, in the fifth position (behind retaining good health -6.75 , domestic bliss -6.73 , decent life -6.54 , and education 6.43). For students, significantly more important than for doctors were success and fame $(p=0.0294)$. Doctors statistically more appreciated a decent life $(p=0.0030)$.

Version B of the same question was "Which of the values listed below are the most important in life for you?". Respondents could choose three of 17 options. Ninety-six students and 80 doctors answered this question correctly. It is noticeable (Fig. 3) that both groups deemed retaining good health and domestic bliss as most important in life, which was consistent with the results of part A of this question. Most valuable for students were: domestic bliss (66\%), retaining good health (35\%), and helping other people (34\%); and for doctors: domestic bliss (75\%), retaining good health (48\%), and profession $(29 \%)$. In order to conduct statistical analysis of the results obtained Spearman's coefficient was used $\left(r_{s}=0.78\right)$. The variables strongly correlate, but the correlation is not full.

In the third question respondents were asked to choose which features they value most in life. This question also had two versions. In version A the question was "Which of the features listed below is the most important 


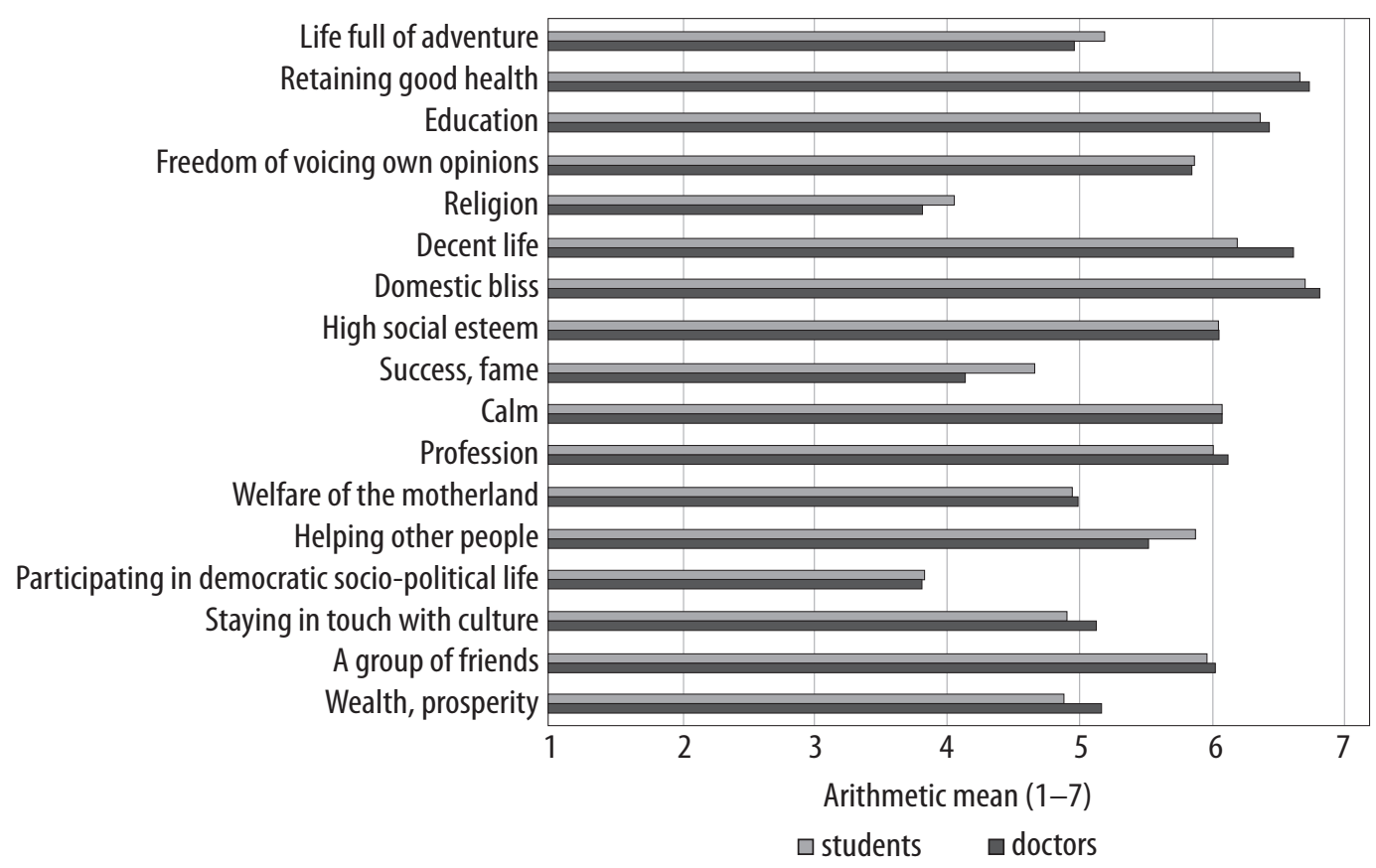

FIGURE 2. The meaning of life values listed above in subjective opinion of the respondents

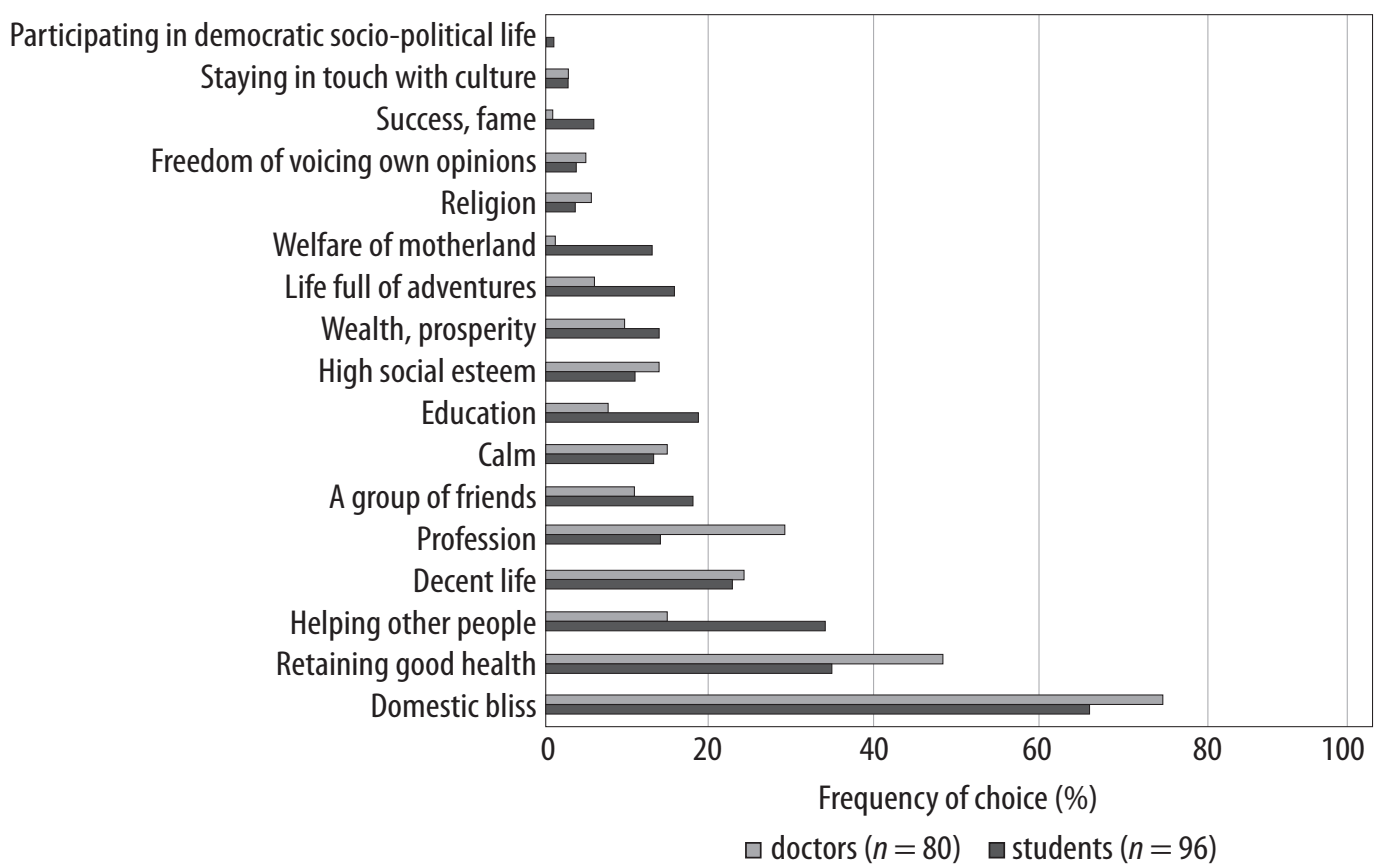

FIGURE 3. A subjective opinion on the importance of life values (choice limited to three values)

for you in everyday life?" Respondents could choose only one option. Three the most commonly chosen answers in the two groups are shown in Table 2. The students ranked family love first (44\%), followed by respect for other people (23\%), and assiduity together with honesty $(8 \%)$. Doctors listed the features in the following order: family love (55\%), respect for other people (13\%), and honesty (11\%). Spearman's coefficient was again used to assess the correlation of the ranks $\left(r_{s}=0.74\right)$. Such a result means that both groups chose similar but not identical variables.
In version B the question was "Which of the features listed below are significantly important to you in everyday life?" Respondents could choose five options. Students most often marked: respect for other people (72\%), family love (67\%), honesty (63\%), fidelity (50\%), and assiduity (44\%). According to doctors, the most significant were family love $(74 \%)$, respect for other people (65\%), honesty (64\%), assiduity (39\%), and tolerance (39\%). With a calculated $r_{s}=0.83$, the correlation can be described as strong. Students and doctors cherished similar values. The results are shown in Table 2. 
TABLE 2. Declared significance of features important in life

\begin{tabular}{|c|c|c|c|c|c|c|}
\hline \multirow[t]{3}{*}{ Options } & $\begin{array}{l}\text { Students } \\
(n=132)\end{array}$ & $\begin{array}{l}\text { Doctors } \\
(n=71)\end{array}$ & $\begin{array}{c}\text { Total } \\
(n=203)\end{array}$ & $\begin{array}{l}\text { Students } \\
(n=96)\end{array}$ & $\begin{array}{l}\text { Doctors } \\
(n=80)\end{array}$ & $\begin{array}{c}\text { Total } \\
(n=176)\end{array}$ \\
\hline & \multicolumn{6}{|c|}{ in $\%$} \\
\hline & \multicolumn{3}{|c|}{ Choice limited to 1 answer (questionnaire A) } & \multicolumn{3}{|c|}{ Choice limited to 5 answers (questionnaire B) } \\
\hline Living life to the full & 5 & - & 3 & 28 & 20 & 24 \\
\hline Family love & 44 & 55 & 48 & 67 & 74 & 70 \\
\hline Patriotism & 3 & - & 2 & 14 & 3 & 9 \\
\hline Assiduity & 8 & 7 & 8 & 44 & 39 & 41 \\
\hline Sincerity & 2 & 1 & 2 & 38 & 26 & 32 \\
\hline Mettle & - & - & - & 9 & 9 & 9 \\
\hline Respect for the law & - & - & - & 8 & 18 & 13 \\
\hline Religiosity & - & - & - & 10 & 5 & 8 \\
\hline Smartness & 2 & - & 1 & 20 & 1 & 11 \\
\hline Respect for other people & 23 & 13 & 20 & 72 & 65 & 69 \\
\hline Tolerance & 4 & 4 & 4 & 23 & 39 & 30 \\
\hline Honesty & 8 & 11 & 9 & 63 & 64 & 63 \\
\hline Fidelity & 1 & 3 & 1 & 50 & 29 & 40 \\
\hline No answer & - & 6 & 2 & 1 & 6 & 3 \\
\hline Total & 100 & 100 & 100 & & NA & \\
\hline Spearman's $\rho$ & \multicolumn{2}{|c|}{0.74} & NA & \multicolumn{2}{|c|}{0.83} & NA \\
\hline
\end{tabular}

NA-Not applicable

\section{DISCUSSION}

Being a doctor demands vast specialist knowledge as well as a proper ethical attitude. The presented study showed elements of value system represented by medical students and actively working specialists (residents and paediatricians as well as paediatric nephrologists, allergists, orthopaedists, and surgeons). Discussion focuses not only on the position in life of profession but also on ethical deterioration as well as work/life balance phenomena. Those have been taken into account because work is undoubtedly a part of life that needs an ethical foundation and tends to influence private life significantly [6]. What is more, the topic of our study was so unique that literature proved to be scarce.

On the basis of a literature search on value systems represented by students of medicine and doctors, one can judge that the ethical deterioration phenomenon is being extensively analysed. And it is not a novel but a theme that interested researchers years ago. In the beginning of the 1990s Hebert et al. in Toronto conducted two studies on medical students of different years $[7,8]$. In both groups it was proven that students of higher years had greater difficulty with identifying ethical issues. During those studies different clinical situations were presented and the task was to spot ethical issues within them. Students were asked to identify ethically difficult situations and list them. The lower the year of studies, the better the identification of issues appeared [7, 8].

When attempting to discuss ethical attitude among doctors and medical students, it is vital to mention moral development according to Kohlberg [9]. Traditionally it distinguishes three levels: preconventional, conventional, and postconventional [9]. During the process of achieving moral maturity, individuals experience all stages. From the very basic strategy of avoiding punishment typical for the preconventional stage to the very distinct and advanced part of postconventional level when unity of ethics and self exists. On the conventional level a hallmark of an action's righteousness is its acceptance by the authority.

The conventional level is best characterised by deeds congruent with the group's world-view. To exemplify this, we take teenagers and young adults into consideration. Their individual behaviour is strongly attached to the opinion of their peers. This is the time when similar issues may be solved analogically owing to the process of conclusion. Undoubtedly, academic doctors' attitudes are crucial since the formative years for students are not yet finished [10]. The aim of the presented study was to compare the value systems represented by medical students and doctors. Also, the place of profession in their hierarchy of values was estimated. It was proven that the sources of normative systems as well as the position of 
profession in the hierarchy of values are parallel for medical students and doctors.

Being on a post-conventional level is the time when guidance of ethical values created throughout life becomes possible [9]. Even though still a part of a group identification with common opinions and attitudes mitigates [9]. Instead of blindly following others, individuals perceive their affiliation as a privilege to possess rights and duties. There also exists a sublevel of moral development when dignity and human rights become integrated with the individual's personality [11]. Yet achieving such an ability is not possible for everyone. Therefore, not every student of medicine can boast an utterly autonomic value system that guides his/her behaviour $[12,13]$. Hence role models represented by academic doctors are pivotal. What needs to be added here is that there is no place for authorities in the value system according to the respondents, and, because medicine teaches humility first and foremost, the role models become more important.

To sum up, in the presented study it was proven that value systems typical for medical students and doctors are parallel. Even though young doctors are still completing stages of moral development, behavioural patterns they observe should be supportive. Without doubt the ethical deterioration phenomenon is not present in the group we studied.

However, ethical deterioration phenomenon is undoubtedly an inspiring issue to study as well as a locus of minoris resistentiae where interventions are required. At the same time the significance of ethical education is being highlighted and teaching ethics is becoming more and more essential [14].

Moreover, it exceptionally transpired that profession itself, in the hierarchy of values that are pivotal in life, is not among the leading ones. Yet when the choice was limited to three values, profession succeeded domestic bliss and retaining good health among doctors. On the other hand, medical students placed helping other people in third place. It is therefore obvious that profession for doctors is closely connected with the identity of the occupational group because it surmounts other aspects of life. In the face of resignation of some values in the hierarchy, calm, decent life, and having a group of friends will be preceded by profession. Nonetheless, professional ethos and satisfaction from working are unsatisfactory according to the results presented in the article "Besieged fortress syndrome" [5]. As for the students, the fact that they are still completing the levels of moral development threatens the final result of formation. The unfinished process may be blurred by improper role models or difficult experiences.

Apart from ethical deterioration phenomenon, worklife balance issue appears in the literature on ethical systems. To exemplify the problem with the true imbalance of work and life, let us refer to a British study from 2015. An upsurge of protest movements among young doctors hit Britain a few years ago. It was evoked by the imposing of even more duties on junior doctors owing to junior doctors' contracts. In the study conducted at the time in Britain a striking imbalance between life and work was demonstrated [6]. What is more, possessing a private life was entirely impossible, hence work and job duties were pervading. Accordingly, stress connected with the abundance of duties at work as well as dissatisfaction from blatant deprivation of private life wielded a negative impact on the participants of the study. A feeling of "dehumanisation" and lack of support from family and friends exerted a negative influence on professional life as well as the process of education [6]. Unfortunately, this problem seemed to affect young mothers the most. Possibilities to work part-time are scarce, and young mothers too often endure discrimination at work [6].

In the presented study profession did not appear high in the hierarchy of life values. Other aspects of life as domestic bliss, retaining good health, calm, and a decent life were far more important for the respondents, insomuch as work-life balance seems not to be degraded in the studied group, contrary to the data presented above.

Indirectly, on the basis of our results, we can conclude that many values are more precious than work. In reference to the question about values, it is obvious that home prosperity and maintaining good health are, for medical students and doctors, far more valuable than profession. In the balance between work and life simply means more. In the question about features most desired in life, assiduity was placed behind family love and respect for other people. Doctors answered similarly, but also honesty preceded assiduity. According to the results of the presented study, profession is not a central part of life for students or for doctors. Is it congruent with the level of work and life satisfaction? The results of the presented study are not enough to answer this question.

One question in the questionnaire assessed axiological sources. Students and doctors answered undoubtedly similarly. "Great influence" was most commonly attributed to two sources, namely parents and one's own reflections. These results are congruent with a study conducted by CBOS in 2010, which also proved that for most Poles parents and one's own reflections are the foundation of ethical rules presented in life [1].

What is inconsistent with the study conducted by CBOS is that grandparents as a source of axiological foundation were ranked third by medical students and doctors. In the CBOS study more important than grandparents were pope John Paul II and religious rules [1]. In the presented study religion as such was attributed a small influence. Whether it is good or bad that for medical professionals faith is not a basic normative source is beyond the scope of the article.

\section{CONCLUSIONS}

To sum up, it is undoubtedly edifying to discover that professional work for medical students and doctors deal- 
ing with children holds a high place in the system of values, but it was not the most important thing in life. Values such as domestic bliss, retaining good health, decent life, or education were far more important. Bearing in mind that satisfaction from working as a doctor is poor and the sense of social injustice is strong, it is still ethics, patient's welfare, and the will to help that create the axis of medical professionals' actions. Finally, in the conducted study the position of values mentioned above in life did not change during the education and professional development of paediatricians. That conclusion drawn from this single-centre study cannot be generalised and applied to all paediatricians and other specialist doctors working in Poland.

\section{LIMITATIONS OF THE STUDY}

The authors ought to admit several limitations of the study. Firstly, it was a single-centre study, although the analysing doctors represented a range of departments in our centre. Secondly, it has already been five years since the questionnaire was conducted. Finally, women dominated in the population, which was not taken into account, excluding diminishing the statistical value of the study when dividing the respondents into more than two groups.

\section{DISCLOSURE}

The authors declare no conflict of interest.

\section{REFERENCES}

1. Boguszewki R. Co jest ważne, co można, a czego nie wolno - normy i wartości w życiu Polaków. Komunikat z badań CBOS BS/99/2010. Warszawa 2010.

2. Martinsen E. Harm in the absence of care: Towards a medical ethics that cares. Nurs Ethics 2011; 18: 174-183.

3. Cybulska A. Prestiż zawodów. Komunikat z badań CBOS BS/164/2013. Warszawa 2013.

4. Falkowska M. Prestiż zawodów. Komunikat z badań CBOS BS/32/99. Warszawa 1999.

5. Stempień J, Tkaczyk M. Besieged fortress syndrome? Occupational group of physicians and medicine students and the problem of social reception of health care system in Poland. Acta Universitatis Lodziensis. Folia Sociologica 2016. DOI: 56. 10.18778/0208600X.56.08.

6. Rich A, Viney R, Needleman S, et al. „You can't be a person and a doctor": the work-life balance of doctors in training - a qualitative study. BMJ Open 2016; 6: e013897.

7. Hebert P, Meslin EM, Dunn EV, et al. Evaluating ethical sensitivity in medical students: using vignettes as an instrument. J Med Ethics 1990; 16: 141-145.

8. Hebert PC, Meslin EM, Dunn EV. Measuring the ethical sensitivity of medical students: a study at the University of Toronto. J Med Ethics 1992; 18: 142-147.

9. Kohlberg L. Stages and aging in moral development - some speculations. Gerontologist 1973; 13: 497-502.
10. Pellegrino ED. Professionalism, profession and the virtues of the good physician. Mt Sinai J Med 2002; 69: 378-384.

11. Branch WT Jr. Supporting the moral development of medical students. J Gen Intern Med 2000; 15: 503-508.

12. Kohlberg L. The Psychology of Moral Development: The Nature and Validity of Moral Stages. Harper \& Row, San Francisco, Calif 1984; 170-205.

13. Kohlberg L. The Philosophy of Moral Development: Moral Stages and the Idea of Justice. Harper \& Row, San Francisco, Calif 1981.

14. Stites SD, Clapp J, Gallagher S, et al. Moving beyond the theoretical: Medical Students' Desire for Practical, Role-Specific Ethics Training. AJOB Empir Bioeth. 2018; 9: 154-163 